\title{
Effect of Psychotropic Drugs on the 21-Hydroxylation of Neurosteroids, Progesterone and Allopregnanolone, Catalyzed by Rat CYP2D4 and Human CYP2D6 in the Brain
}

\author{
Toshiro Niwa, ${ }^{a}$ Kazushi Okada, ${ }^{a, b}$ Toyoko Hiroi, ${ }^{a}$ Susumu Imaoka, ${ }^{b}$ Shizuo Narimatsu, ${ }^{c}$ and \\ Yoshihiko FUnAE*,a \\ ${ }^{a}$ Department of Chemical Biology, Osaka City University Graduate School of Medicine; 1-4-3 Asahimachi, Abeno-ku, \\ Osaka 545-8585, Japan: ${ }^{b}$ Nanobiotechnology Research Center and Department of Bioscience, School of Science and \\ Technology, Kwansei Gakuin University; 2-1 Gakuen, Sanda 669-1337, Japan: and ' Laboratories of Health Chemistry, \\ Graduate School of Medicine, Dentistry and Pharmaceutical Sciences, Okayama University; Tsushima-naka, Okayama \\ 700-8530, Japan. Received October 22, 2007; accepted January 8, 2008; published online January 10, 2008
}

\begin{abstract}
We determined the effects of psychotropic drugs on the cytochrome P450 2D (CYP2D)-mediated 21-hydroxylation of progesterone (PROG) and allopregnanolone (ALLO) with the goal of clarifying whether neurosteroid levels are affected by psychotropic drugs in the brain. PROG or ALLO was incubated with rat CYP2D4 or human CYP2D6 in the presence of typical psychotropic drugs, fluoxetine, imipramine, desipramine, mazindol, and GBR12909, and the 21-hydroxylated metabolites of PROG and ALLO were determined by high performance liquid chromatography and liquid chromatography-tandem mass spectrometry, respectively. Fluoxetine competitively inhibited CYP2D4-mediated PROG 21-hydroxylation and increased both $K_{\mathrm{m}}$ and $V_{\max }$ values of CYP2D6-mediated PROG 21-hydroxylation. In addition, fluoxetine competitively inhibited ALLO 21-hydroxylation mediated by CYP2D4 and CYP2D6. Imipramine, desipramine, mazindol, and GBR12909 competitively inhibited PROG 21-hydroxylation mediated by CYP2D4 and/or CYP2D6, and all psychotropic drugs inhibited ALLO 21-hydroxylation mediated by CYP2D4 and/or CYP2D6. The inhibition constants $\left(K_{i}\right.$ values) of imipramine, desipramine, and mazindol against the 21-hydroxylation of PROG and ALLO by CYP2D6 were lower than those by CYP2D4. These results indicate that psychotropic drugs including fluoxetine affected the metabolism of neurosteroids, such as PROG and ALLO in the brain, suggesting that the regulation of the neurosteroid levels is modified by central nervous system-active drugs that inhibit brain CYP2D isoforms.
\end{abstract}

Key words cytochrome P450 2D4; cytochrome P450 2D6; psychotropic drug; progesterone 21-hydroxylation; allopregnanolone 21-hydroxylation; fluoxetine

Progesterone (PROG) not only is one of the female steroid hormones secreted from the placenta and corpus luteum but also has various functions in the central nervous system as a neurosteroid in the brain. ${ }^{1,2)}$ PROG has the ability to increase myelin-specific protein levels and to enhance the $\gamma$-aminobutyric acid (GABA)-induced chloride current, ${ }^{2,3)}$ and the PROG metabolites, $3 \alpha$-hydroxy-5 $\alpha$-pregnan-20-one (allopregnanolone, ALLO) and $3 \alpha, 5 \alpha$-tetrahydrodeoxycorticosterone, act as positive allosteric modulators of GABA type A receptors, and thereby reduce brain excitability and elicit sedative-hypnotic, anxiolytic, and anticonvulsant effects. ${ }^{4)}$ These neurosteroids are eliminated via the metabolic pathways, including the hydroxylation at position $\mathrm{C} 21 .{ }^{5)}$

Cytochrome P450s (CYP) comprise a superfamily of enzymes that catalyze the oxidation of a wide variety of xenobiotic chemicals including drugs, carcinogens, and steroids. ${ }^{6-8)}$ In spite of the fact that CYP2D6 constitutes only $2-9 \%$ of constitutively expressed hepatic P450s among humans, $\left.{ }^{9}, 10\right)$ it plays important roles in the metabolism of a wide range of therapeutic agents, including drugs affecting the central nervous system. ${ }^{5,8,11,12)}$ Interestingly, CYP2D6 is expressed in the human brain, especially the midbrain, ${ }^{13)}$ as well as in the liver. In addition, CYP2D4 mRNA is expressed in the rat brain, ${ }^{14,15)}$ and the reverse transcriptase-polymerase chain reaction (RT-PCR) product from CYP2D4, the predominant CYP2D isoform in the rat brain, is more abundant in the cerebellum, striatum, pons, and medulla oblongata. ${ }^{16)}$ However, the physiological and pharmacological functions of CYP2D isoforms in the brain are still unknown.
We have demonstrated that CYP2D6 catalyzes the $2 \beta, 6 \beta-$, $16 \alpha$-, and 21-hydroxylation of PROG, ${ }^{17,18)}$ and that PROG $2 \beta$-and 21-hydroxylation activities in rat brain microsomes are completely inhibited by CYP2D antibodies, suggesting that CYP2D may be involved in the regulation (metabolism and/or synthesis) of endogenous neuroactive steroids, such as PROG and its derivatives, in the brain. ${ }^{18)}$ Additionally, we have reported that the 21-hydroxylation of ALLO as well as PROG and $17 \alpha$-PROG is catalyzed by CYP2D isoforms in the brain. ${ }^{5,15)}$

Many of the psychotropic drugs, including fluoxetine (a selective serotonin reuptake inhibitor, SSRI), imipramine (a tricyclic antidepressant and a serotonin and noradrenaline reuptake inhibitor), and desipramine (a noradrenaline reuptake inhibitor), are metabolized by CYP2D and/or inhibit the CYP2D-mediated metabolic activities. ${ }^{8,15,19-23)}$ One of the dopamine uptake sites in the brain displays high affinity for dopamine uptake inhibitors such as mazindol, a noradrenaline reuptake inhibitor. ${ }^{24,25)}$ The other site displays rather high affinity for piperizine derivatives and has been termed the piperazine acceptor site. ${ }^{26)}$ GBR12909 (vanoxerine) is a potent inhibitor of both the binding of GBR12935, a piperizine derivative, and CYP2D6 activity. ${ }^{27)}$ We have demonstrated that the GBR12935 binding is reduced by CYP2D substrates and inhibitors, including imipramine and desipramine. ${ }^{28)}$ Therefore, we investigated the effects of these typical psychotropic drugs on the CYP2D-mediated 21-hydroxylation of PROG and ALLO to clarify whether neurosteroid levels are affected by psychotropic drugs in the brain. 


\section{MATERIALS AND METHODS}

Materials PROG, ALLO, 21-hydroxy-PROG, 21-hydroxy-ALLO, fluoxetine, and mazindol were obtained from Sigma-Aldrich (St. Louis, MO, U.S.A.). GBR12909, 5- $\alpha$ pregnan-3- $\alpha$-ol-28-one-17,21,21,21- $d_{4}$, and NADPH were purchased from Research Biochemicals International (Natick, MA, U.S.A.), Cambridge Isotope Laboratories, Inc. (Andover, MA, U.S.A.), and Oriental Yeast Co., Ltd. (Tokyo, Japan), respectively. Other reagents and organic solvents were obtained from Wako Pure Chemical Industries (Osaka, Japan).

CYP2D4 and CYP2D6 were expressed in Saccharomyces cerevisiae and the microsomal fractions were prepared from the yeast cells as described previously. ${ }^{15,18)}$

Enzyme Assay and Quantification of 21-Hydroxylated Metabolites of PROG and ALLO Progesterone 21-hydroxylation activity was measured by the method described previously ${ }^{29)}$ with a minor modification. The incubation mixture consisted of microsomes from cells containing recombinant CYP2D4 $(50 \mathrm{pmol} / \mathrm{ml})$ or CYP2D6 $(30 \mathrm{pmol} / \mathrm{ml}), 2,5$, 10 , or $20 \mu \mathrm{M}$ (for CYP2D4) or $4,10,25$, or $100 \mu \mathrm{M}$ (for CYP2D6) PROG, $0,2,5,20$ or $50 \mu \mathrm{m}$ of the tested psychotropic drug, $1 \mathrm{~mm}$ NADPH, and $100 \mathrm{~mm}$ potassium phosphate buffer ( $\mathrm{pH} 7.4)$ in a final volume of $0.5 \mathrm{ml}$. After a 3min preincubation at $37^{\circ} \mathrm{C}$, the reaction was started by adding NADPH. Incubation was carried out at $37^{\circ} \mathrm{C}$ for $10 \mathrm{~min}$ and the reaction was terminated by the addition of $2 \mathrm{ml}$ of ethyl acetate. 21-Hydroxyprogesterone was determined by HPLC, and the elution of the analytes was monitored by UV detection $(240 \mathrm{~nm})^{29)}$.

For the assay of ALLO 21-hydroxylation activity, the incubation mixture consisted of microsomes from cells containing recombinant CYP2D4 $(10 \mathrm{pmol} / \mathrm{ml})$ or CYP2D6 (50 $\mathrm{pmol} / \mathrm{ml}), 2,5,20$, or $50 \mu \mathrm{M}$ ALLO, $0,2,10$, or $50 \mu \mathrm{M}$ of the tested psychotropic drug, $1 \mathrm{~mm} \mathrm{NADPH}$, and $100 \mathrm{~mm}$ potassium phosphate buffer ( $\mathrm{pH}$ 7.4) in a final volume of $0.5 \mathrm{ml}$. After a 2-min preincubation at $37^{\circ} \mathrm{C}$, the reaction was started by adding NADPH. Incubation was carried out at $37^{\circ} \mathrm{C}$ for $5 \mathrm{~min}$, and the reaction was terminated by the addition of $2 \mathrm{ml}$ of ethyl acetate and $10 \mu \mathrm{l}$ of $2 \mathrm{~mm} 5$ - $\alpha$-pregnan-3- $\alpha$-ol28 -one-17,21,21,21- $d_{4}$ was added as an internal standard. The mixture was shaken and centrifuged at $1900 \boldsymbol{g}$ for $5 \mathrm{~min}$. The organic phase $(1.5 \mathrm{ml})$ was evaporated under reduced pressure, and residue was dissolved immediately in $100 \mu 1$ of methanol. Liquid chromatography/tandem mass spectrometry (LC/MS/MS) was performed using an Agilent 1100 series HPLC system (Agilent Technologies, Inc., Santa Clara, CA, U.S.A.) coupled with the 4000 Q TRAP LC/MS/MS system (Applied Biosystems, Foster City, CA, U.S.A.) operating in MRM+ mode, with Analyst 1.4 running in multiple reaction monitoring mode (two reactions monitored simultaneously; 21-hydroxy-ALLO, 357.5>357.5; 5- $\alpha$-pregnan-3$\alpha$-ol-28-one-17,21,21,21- $d_{4}, 305.5>287.5$; dwell time of 500 $\mathrm{ms})$. A ZORBAX Eclipse XDB-C18 $(4.6 \mathrm{~mm} \times 150 \mathrm{~mm}, 5$ $\mu \mathrm{m}$, Agilent Technologies, Inc.) was used as an analytical column, and the mobile phase was eluted at a flow rate of $0.2 \mathrm{ml} / \mathrm{min}$ as follows. The mobile phase was $0.1 \%$ sodium acetate as eluent $\mathrm{A}$ and methanol containing $0.1 \%$ sodium acetate as eluent $\mathrm{B}$. Gradient conditions were $0-15 \mathrm{~min}$, $70-90 \%$ B (linear gradient); $15-20 \mathrm{~min}, 90 \% \mathrm{~B} ; 20-$
$20.1 \mathrm{~min}, 90-70 \% \mathrm{~B}$ (linear gradient); $20.1-30 \mathrm{~min}, 70 \%$ B. The retention times of 21-hydroxy-ALLO and 5- $\alpha$ pregnan-3- $\alpha$-ol-28-one-17,21,21,21- $d_{4}$, were $11.7 \mathrm{~min}$ and $16.3 \mathrm{~min}$, respectively, and the detection limit of 21-hydroxyALLO in the incubation mixture was $0.2 \mathrm{~nm}$, and the coefficients of variation were less than $7.4 \%$.

Data Analysis In preliminary experiments, the linearity of the reaction with the protein concentration and incubation time was confirmed for each set of assay conditions. All data were analyzed using the mean of duplicate determinations. The inhibition constant $\left(K_{\mathrm{i}}\right)$ was estimated by fitting the inhibition curves to Eq. 1 or Eq. 2, when the inhibition type was competitive or noncompetitive, respectively, as follows:

$$
\begin{aligned}
& v=V_{\text {max }} \cdot S /\left\{K_{\mathrm{m}}\left(1+I / K_{\mathrm{i}}\right)+S\right\} \\
& v=\left\{V_{\max } /\left(1+I / K_{\mathrm{i}}\right) \cdot S\right\} /\left(K_{\mathrm{m}}+S\right)
\end{aligned}
$$

where $v, S, I, V_{\max }$, and $K_{\mathrm{m}}$ are the velocity of the metabolite formation and the concentrations of substrate and inhibitor, the maximum velocity of the metabolite formation, and the apparent Michaelis-Menten constant, respectively. These equations were fitted to data by means of a computer program (Microcal Origin, version 5.0J, Origin LabCorp, Northampton, MA, U.S.A.), and the fitting evaluation was carried out using Akaike's information criterion. ${ }^{30)}$

\section{RESULTS}

Inhibition constant $\left(K_{\mathrm{i}}\right)$ values of psychotropic drugs for PROG 21-hydroxylation by CYP2D4 and CYP2D6 are summarized in Table 1. All psychotropic drugs except for fluoxetine competitively inhibited PROG 21-hydroxylation mediated by CYP2D4 or CYP2D6, and the $K_{\mathrm{i}}$ values of imipramine, desipramine, and mazindol against the 21-hydroxylation activity by CYP2D6 (around $1 \mu \mathrm{M}$ ) were lower than those by CYP2D4. Fluoxetine competitively inhibited CYP2D4-mediated PROG 21-hydroxylation, whereas the drug increased both $K_{\mathrm{m}}$ and $V_{\max }$ values of CYP2D6-mediated PROG 21-hydroxylation (Table 2).

$K_{\mathrm{i}}$ values of psychotropic drugs for ALLO 21-hydroxylation by CYP2D4 and CYP2D6 are shown in Table 3. Fluoxetine competitively inhibited the 21-hydroxylation mediated by CYP2D4 or CYP2D6. Imipramine, desipramine, mazindol, and GBR12909 competitively or noncompetitively inhibited ALLO 21-hydroxylation mediated by CYP2D4 or CYP2D6, except that no inhibition by mazindol against CYP2D4-mediated activity was observed. The $K_{\mathrm{i}}$ values of all psychotropic drugs except for GBR12909 against the 21-

Table 1. $K_{\mathrm{i}}$ Values of Psychotropic Drugs for PROG 21-Hydroxylation by CYP2D4 and CYP2D6

\begin{tabular}{lcc}
\hline \hline & \multicolumn{2}{c}{$K_{\mathrm{i}}(\mu \mathrm{M})^{a)}$} \\
\cline { 2 - 3 } & CYP2D4 & CYP2D6 \\
\hline Fluoxetine & 4.8 & $\mathrm{NC}$ \\
Imipramine & 11.0 & 1.4 \\
Desipramine & 7.0 & 1.0 \\
Mazindol & $>50$ & 0.68 \\
GBR12909 & 5.6 & 7.0
\end{tabular}

${ }^{a)}$ Competitive inhibition. NC: not calculated. 
Table 2. Effect of Fluoxetine on PROG 21-Hydroxylation by CYP2D6

\begin{tabular}{cccc}
\hline \hline $\begin{array}{c}\text { Fluoxetine } \\
(\mu \mathrm{M})\end{array}$ & $\begin{array}{c}K_{\mathrm{m}} \\
(\mu \mathrm{M})\end{array}$ & $\begin{array}{c}V_{\max } \\
(\mathrm{pmol} / \mathrm{min} / \mathrm{nmol} \mathrm{CYP})\end{array}$ & $\begin{array}{c}V_{\max } / K_{\mathrm{m}} \\
(\mu \mathrm{l} / \mathrm{min} / \mathrm{nmol} \mathrm{CYP})\end{array}$ \\
\hline 0 & $31.0(100)$ & $65.1(100)$ & $2.10(100)$ \\
0.5 & $49.8(161)$ & $110.5(170)$ & $2.22(106)$ \\
2 & $75.0(242)$ & $177.0(272)$ & $2.36(112)$ \\
5 & $87.3(282)$ & $216.9(333)$ & $2.48(118)$ \\
20 & $100.3(324)$ & $75.2(116)$ & $0.75(36)$ \\
\hline
\end{tabular}

Table 3. $K_{\mathrm{i}}$ Values of Psychotropic Drugs for ALLO 21-Hydroxylation by CYP2D4 and CYP2D6

\begin{tabular}{lcc}
\hline \hline & \multicolumn{2}{c}{$K_{\mathrm{i}}(\mu \mathrm{M})^{a)}$} \\
\cline { 2 - 3 } & CYP2D6 & CYP2D4 \\
\hline Fluoxetine & $9.0^{a)}$ & $2.0^{a)}$ \\
Imipramine & $16.0^{a)}$ & $3.8^{b)}$ \\
Desipramine & $15.7^{a)}$ & $3.3^{a)}$ \\
Mazindol & $>50^{c)}$ & $0.55^{a)}$ \\
GBR12909 & $1.2^{a)}$ & $3.3^{b)}$
\end{tabular}

${ }^{a)}$ Competitive inhibition. ${ }^{b)}$ Noncompetitive inhibition. ${ }^{c}$ No inhibition was observed at $50 \mu \mathrm{M}$.

hydroxylation activity by CYP2D6 $(1-4 \mu \mathrm{M})$ were lower than those by CYP2D4.

\section{DISCUSSION}

We have reported that rat CYP2D4 and human CYP2D6 catalyze the 21-hydroxylation of neurosteroids such as PROG, 17-hydroxy-PROG, and ALLO in the brain. ${ }^{15)}$ Fluoxetine competitively inhibited the 21-hydroxylation of PROG and ALLO mediated by CYP2D4 and CYP2D6 (Tables 1, 3), except that it increased both $K_{\mathrm{m}}$ and $V_{\max }$ values of CYP2D6mediated PROG 21-hydroxylation (Table 2). Imipramine, desipramine, mazindol, and GBR12909 competitively inhibited PROG 21-hydroxylation mediated by CYP2D4 and/or CYP2D6 (Table 1), and all psychotropic drugs inhibited ALLO 21-hydroxylation mediated by CYP2D4 and/or CYP2D6 (Table 3).

Recently, the mean brain level of fluoxetine in healthy volunteers who received $20 \mathrm{mg} / \mathrm{d}$ fluoxetine for 5 weeks determined by fluorine-19 (19-F) magnetic resonance spectroscopy (MRS) was reported to be $25.5 \mu \mathrm{M} .{ }^{31)}$ It is difficult to measure the degree of brain penetration in humans, but animal studies have shown that the brain concentrations of fluoxetine, imipramine, and desipramine are approximately 10-fold higher than the plasma concentrations. ${ }^{32-34)}$ According to the packing insert (Imipramine hydrochloride, Novartis Pharma, 2006, Tokyo, Japan), after oral dosing of 75 $\mathrm{mg}$ imipramine, the maximum plasma concentrations of imipramine and desipramine are $70 \mathrm{ng} / \mathrm{ml}(0.25 \mu \mathrm{M})$ and 29 $\mathrm{ng} / \mathrm{ml}(0.11 \mu \mathrm{M})$, respectively. Although the plasma or brain concentrations of other psychotropic drugs are unknown, it can be speculated that the expected brain concentrations of fluoxetine, imipramine, and desipramine are comparable to or higher than the $K_{i}$ values $(1-16 \mu \mathrm{M})$. Therefore, the present results suggest that psychotropic drugs including fluoxetine affected the metabolism of neurosteroids such as PROG and ALLO in the brain, and that the regulation of the neuro- steroid levels is modified by central nervous system-active drugs that inhibit brain CYP2D isoforms. To our knowledge, this is the first proposal about a possible effect of the psychotropic drugs that inhibit CYP2D activities on the metabolism of neurosteroids. Although we investigated the effects of only five typical psychotropic drugs, it is possible to speculate that other psychotropic drugs that are metabolized by CYP2D and/or inhibit CYP2D activities also might affect neurosteroid levels in the brain. In addition, the $K_{\mathrm{i}}$ values of imipramine, desipramine, and mazindol against the 21-hydroxylation of PROG and ALLO by CYP2D6 were lower than those by CYP2D4 (Tables 1, 3), suggesting that the effect of the metabolism of neurosteroids by these psychotropic drugs is more potent in humans than in rats. Further studies on the effects of these drugs on the neurosteroid levels in the brain are required.

Interestingly, fluoxetine increased not only the $K_{\mathrm{m}}$ value but also the $V_{\max }$ value of CYP2D6-mediated PROG 21hydroxylation (Table 2). A number of investigators have demonstrated the activation of oxidative metabolism of many compounds catalyzed by CYP3A4, whereas the detailed mechanism is still unknown. ${ }^{35-37)}$ However, there are few reports about the activation of the reactions mediated by CYP2D6. We have reported that steroid hormones, such as progesterone and testosterone, activate the metabolic activities of several CYP3A4 substrates, that in vitro activation patterns are substrate-dependent, and that the selection of enzyme source (liver microsomes or recombinant CYP) can affect the activation. ${ }^{37}$ The detail mechanism for the activation of the reactions mediated by CYP2D6 as well as CYP3A4 is still unknown, and further investigations are required.

Of interest is the observation made here that imipramine noncompetitively inhibited the ALLO 21-hydroxylation mediated by CYP2D6, whereas its metabolite, desipramine, competitively inhibited the reaction (Table 3). There are few reports comparing the inhibition type of imipramine and desipramine except that both imipramine and desipramine competitively inhibit venlafaxine $O$-demethylation by human liver microsomes. ${ }^{38)}$ In addition, GRB12909 inhibited the 21-hydroxylation of PROG and ALLO by CYP2D4 and CYP2D6, even though CYP3A4 is the major enzyme responsible for the biotransformation of GBR12909. ${ }^{39)}$ It is well known that quinidine, a typical inhibitor of CYP2D, is predominantly metabolized by CYP3A4. ${ }^{40)}$

In summary, the present results suggest that psychotropic drugs that inhibit CYP2D activity affect the metabolism of neurosteroids such as PROG and ALLO in the brain, and that the regulation of the neurosteroid levels is modified by the psychotropic drugs.

\section{REFERENCES}

1) Baurieu E. E., Psychoneuroendocrinology, 23, 963-987 (1998).

2) Wu F. S., Gtibbs T. T., Farb D. H., Mol. Pharmacol., 37, 597-602 (1990).

3) Jung-Testas I., Do Thi A., Koenig H., Desarnaud F., Shazand K., Schumacher M., Baulieu E. E., J. Steroid Biochem. Mol. Biol., 69, 97-107 (1999).

4) Paul S. M., Purdy R. H., FASEB J., 6, 2311-2322 (1992).

5) Funae Y., Kishimoto W., Cho T., Niwa T., Hiroi T., Drug Metab. Pharmacokin., 18, 337-349 (2003).

6) Gonzales F. J., Pharmacol. Ther., 45, 1-38 (1990).

7) Guengerich F. P., FASEB J., 6, 745-748 (1992). 
8) Rendic S., Drug Metab. Rev., 34, 83-448 (2002).

9) Shimada T., Yamazaki H., Mimura M., Inui Y., Guengerich F. P., J. Pharmacol. Exp. Ther, 270, $414-423$ (1994).

10) Imaoka S., Yamada T., Hiroi T., Hayashi K., Sakaki T., Yabusaki Y., Funae Y., Biochem. Pharmacol., 51, 1041-1050 (1996).

11) Cholerton S., Daly A. K., Idle J. R., Trends Pharmacol. Sci., 13, 434 439 (1992).

12) Niwa T., Shiraga T., Mitani Y., Terakawa M., Tokuma Y., Kagayama A., Drug Metab. Dispos., 28, 1128-1134 (2000).

13) McFadyen M. C. E., Melvin W. T., Murray G. I., Biochem. Pharmacol., 55, 625-830 (1998).

14) Hiroi T., Imaoka S., Chow T., Funae Y., Biochim. Biophys. Acta, 1380, 305-312 (1998).

15) Kishimoto W., Hiroi T., Shiraishi M., Osada M., Imaoka S., Kominami S., Igarashi T., Funae Y., Endocrinology, 145, 699-705 (2004).

16) Komori M., Biochem. Biophys. Res. Commun., 196, $721-728$ (1993).

17) Niwa T., Yabusaki Y., Honma K., Matsuo N., Tatsuta K., Ishibashi F., Katagiri M., Xenobiotica, 28, 539-547 (1998).

18) Hiroi T., Kishimoto W., Chow T., Imaoka S., Igarashi T., Funae Y., Endocrinology, 142, 3901-3908 (2001).

19) Brosen K., Zeugin T., Meyer U. A., Clin. Pharmacol. Ther, 49, 609617 (1991).

20) Hiemke C., Hartter S., Pharmacol. Ther, 85, 11-28 (2000)

21) Shin J., Park J., Kim M., Shon J., Yoon Y., Cha I., Lee S., Oh S., Kim S., Flockhart D. A., Drug Metab. Dispos., 30, 1102-1107 (2002).

22) Niwa T., Shiraga T., Ishii I., Kagayama A., Takagi A., Biol. Pharm. Bull., 28, 1711-1716 (2005).

23) Mandrioli R., Forti G. C., Raggi M. A., Curr. Drug Metab., 7, 127133 (2006).

24) Reith M. E. A., Sershen H., Lajtha A., Life Sci., 27, 1055-1062 (1980).
25) Javitch J. A., Blaustein R. O., Snyder S. H., Eur. J. Pharmacol., 106, 455-456 (1983).

26) Andersen P. H., J. Neurochem., 48, 1887-1896 (1987).

27) Niznik H. B., Tyndale R. F., Sallee F. R., Gonzalez F. J., Hardwick J. P., Inaba T., Kalow W., Arch. Biochem. Biophys., 276, 424-432 (1990).

28) Hiroi T., Imaoka S., Chow T., Yabusaki Y., Funae Y., Biochem. Pharmacol., 53, 1937-1939 (1997).

29) Niwa T., Hiroi T., Tsuzuki D., Yamamoto S., Narimatsu S., Fukuda T., Azuma J., Funae Y., Mol. Brain Res., 129, 117-123 (2004).

30) Akaike H., Transact. Automat. Control, 19, 716-723 (1974).

31) Henry M. E., Schmidt M. E., Hennen J., Villafuerte R. A., Butman M. L., Tran P., Kerner L. T., Cohen B., Renshaw P. F., Neuropsychopharmacology, 30, 1576-1583 (2005)

32) Barkai A. I., Suckow R. F., Cooper T. B., J. Pharmacol. Exp. Ther. 230, 330-335 (1984).

33) Holladay J. W., Dewey M. J., Yoo S. D., Drug Metab. Dispos., 26, 20 24 (1998)

34) Hendset M., Haslemo T., Rudberg I., Refsum H., Molden E., Pharmacopsychiatry, 39, 121-127 (2006).

35) Shou M., Grogan J., Mancewicz J. A., Krausz K. W., Gonzalez F. J., Gelboin H. V., Korzekwa K. R., Biochemistry, 33, 6450-6455 (1994).

36) Hollenberg P. F., Drug Metab. Rev., 34, 17-35 (2002).

37) Niwa T., Shiraga T., Yamasaki S., Ishibashi K., Ohno Y., Kagayama A., Xenobiotica, 33, 717-729 (2003).

38) Ball S. E., Ahern D., Scatina J., Kao J. Br. J. Clin. Pharmacol., 43 619-626 (1997).

39) Cherstniakova S. A., Bi D., Fuller D. R., Mousiak J. Z., Collins J. M., Cantilena L. R., Drug Metab. Dispos., 29, 1216-1220 (2001).

40) Newton D. J., Wang R. W., Lu A. Y. H., Drug Metab. Dispos., 23, 154-158 (1995). 